\title{
The blink reflex test does not show abnormalities in a large group of patients with chronic migraine
}

\author{
0 teste do reflexo do piscamento não mostra alterações em um grande grupo de \\ pacientes com enxaqueca crônica
}

Joseph Bruno Bidin Brooks ${ }^{1,2}$, Yara Dadalti Fragoso'

\begin{abstract}
The blink reflex - a simple, non-invasive and inexpensive test - may be indicative of lesions or dysfunctions of the brainstem, and particularly assesses the trigeminal-facial arch. Results from alterations of the blink reflex in patients with headaches have provided controversial data. Method: Registration of the waves R1 and R2 (ipsilateral to the stimulus) and R2c (contralateral to the stimulus) by electroneuromyography. Results: A large number of controls $(n=160)$ and patients with chronic migraine $(n=160)$ were studied. No significant differences were observed between the two groups. Conclusion: It is possible that this relatively simple and primitive reflex is not affected unless there is significant damage to the brainstem.
\end{abstract}

Keywords: blink reflex, headache, migraine, brainstem, trigeminal nucleus.

\section{RESUMO}

O reflexo do piscamento é um teste simples, não invasivo de baixo custo que pode direcionar o raciocínio para lesões ou disfunções do traonco cerebral, avaliando particularmente o arco trigêmeo-facial. Resultados de reflexo do piscamento em pacientes com cefaleias têm mostrado dados controversos. Método: Registro das ondas R1 e R2 (ipsilaterais ao estímulo) e R2c (contralateral ao estímulo) por eletroneuromiografia. Resultados: Um grande número de controles $(n=160)$ e pacientes com enxaqueca crônica $(n=160)$ foi avaliado. Não foram encontradas diferenças significativas no reflexo do piscamento entre os dois grupos. Conclusão: É possível que este reflexo, por ser relativamente simples e primitivo, não esteja alterado a menos que ocorram danos significativos no tronco cerebral.

Palavras-chave: reflexo do piscamento, cefaleia, enxaqueca, tronco cerebral, núcleo trigeminal.

\section{INTRODUCTION}

Activation of the trigeminovascular system and sensitization of brainstem trigeminal nuclei are thought to play an important role in migraine and, possibly, in other chronic primary headaches as well. However, studying brainstem function and dysfunction is not an easy task ${ }^{1}$. A variety of nuclei, neuromodulators and pathways integrating at different levels make the task of finding a marker of dysfunction virtually impossible. However, indirect signs of brainstem dysfunction can be obtained from assessment of certain facial reflexes. In order to study the role of the pontine trigeminal nucleus and its interconnections, some electrophysiological reflexes may be tested; one of these is the blink reflex, described in 1896 by Overend ${ }^{2}$. The blink reflex, also known as the orbicularis oculi reflex test, may be indicative of lesions or dysfunctions of the brainstem, and particularly assesses the trigeminal-facial arch. This reflex is elicited by stimulation of the supraorbital nerve on one side of the face, leading to two ipsilateral responses ( $\mathrm{R} 1$ and $\mathrm{R} 2$ ) and one contralateral response (R2c). $\mathrm{R} 1$ represents an oligosynaptic pathway involving the main sensory nucleus of the trigeminal nerve and the intermediate subnucleus of the facial nerve. The second response, R2, involves a pathway of descent to the spinal trigeminal tract. The contralateral response, R2c, reflects the crossing of the brainstem in the medulla and progresses through the reticular formation to elicit a response at the contralateral facial nucleus.

The results obtained from testing the blink reflex in patients with headaches have been very heterogeneous. A lack of habituation to pain stimulus can be observed in migraneurs ${ }^{3.4}$ but not in patients with cluster headache ${ }^{5}$. In studying the latency and amplitude of R2c, some authors have

\footnotetext{
'Department of Neurology, Universidade Metropolitana de Santos, São Paulo SP, Brazil;

${ }^{2}$ PhD student, Universidade Federal do Estado do Rio de Janeiro, Rio de Janeiro RJ, Brazil.

Correspondence: Joseph Bruno Bidin Brooks; Department of Neurology / Medical School, UNIMES; Rua da Constituição 374; 11015 -470 Santos SP - Brasil; E-mail:joseph3b@gmail.com

Conflict of interest: There is no conflict of interest to declare.

Received 15 March 2013; Received in final form 02 May 2013; Accepted 09 May 2013.
} 
been able to identify alterations in these waves in patients with chronic headaches ${ }^{4,6-8}$, while other authors have failed to replicate these results ${ }^{5,-12}$. Furthermore, some authors have only detected alterations in the blink reflex waves during a migraine attack $^{6}$, while others have noted alterations during the inter-attack period in migraineurs ${ }^{4,7,8}$. While some authors have drawn attention to the short latency of the R2c response ${ }^{7}$, others have highlighted enhanced latency for the same R2c wave ${ }^{9}$. Several forms of headache have been studied by these authors, including episodic migraine $e^{4,7,8}$, cluster headache $e^{5}$, hypnic headache ${ }^{12}$, tension-type headache $e^{10,11,13}$ and cervicogenic headache ${ }^{11}$. The results have been contradictory, and all studies published so far have only included a few dozen patients and controls, with typically less than 50 individuals in each group.

No previous study has assessed individuals with chronic daily headache evolving from episodic migraine ${ }^{14}$. These patients might also present alterations in brainstem neurotransmission and general function ${ }^{15}$ that may be detectable using electrophysiological methods of investigation. On the other hand, these patients may have become "habituated" to the chronic pain condition, and brainstem alterations may not be detectable by electrophysiological methods. In addition, the usual pattern of high analgesic consumption by these patients may also affect the facial reflex findings. The aims of the present study were to assess the blink reflex wave patterns in a large group of chronic daily headache sufferers who evolved from primary episodic migraine ${ }^{16}$ and to compare the results with matched control subjects.

\section{METHOD}

This study was approved by the Ethics Committee of the Universidade Metropolitana de Santos, number 020/2011, CAAE 0017.0.161.000-11. The patient group consisted of 160 patients with chronic migraine. All patients frequently used analgesics and anti-inflammatory drugs (but no opioids) and were attending medical consultations in the city of Santos, Brazil. During clinical investigation, the doctors in charge of these cases considered it worth requesting this test. The patients were then referred to our unit, where the test was performed and the results were noted for use in the present study. As an ethical requirement, the patients were given assurances that they could continue to make use of their medications. All of these patients agreed to participate in the study and took the final results to the doctor who ordered the electrophysiological test. The control group consisted of 160 subjects who were attending the EMG laboratory for non-specific complaints, as well as volunteers who were enrolled in the project. All participants were aware of the experimental characteristics of the study. Control subjects who did not sign the test agreement statement, and those previously diagnosed with central or peripheral nerve diseases, earlier cranial nerve lesions, autonomic disturbances or diabetes mellitus, and those using drugs with anti-cholinergic properties, were excluded.

The blink reflex was assessed using two-channel Nicolet Viking Quest EMG equipment (Nicolet Biomedical Inc, San Carlos, CA, USA). All tests were performed by the same medical doctor. The subjects were in a supine position, in a relaxed state and with their eyes open. A ground electrode was placed on the patient's chin. The active recording electrode was placed on the inferior orbital part of the orbicularis oculi, just laterally to the vertical line that can be drawn with the pupils in midposition. The reference recording electrode was placed laterally to the lateral canthus of each eye. Recording electrodes were placed on both sides. The machine settings were as follows: sweep speed $10 \mathrm{~ms} /$ division, sensitivity $100 \mu \mathrm{V} /$ division, and motor filter settings $10 \mathrm{~Hz}$ and $10 \mathrm{kHz}$. Facial nerve studies were initially performed on each subject to ensure that normal motor latency and amplitude could be obtained on each side and that there was no damage to the peripheral part of the efferent loop of the reflex. The supraorbital branches of the trigeminal nerve were stimulated on each side with a stimulus of 20-45 mA intensity and $0.1-0.3 \mathrm{~ms}$ duration. The stimulus intensity was increased in steps of $5 \mathrm{~mA}$ until a reliable and reproducible response was obtained. Bilateral recordings were made simultaneously.

In order to obtain the R1, R2, and R2c contralateral latencies and an unambiguous response after each individual's threshold stimulus intensity had been obtained, 10 responses were superimposed from each side and the median of these responses was chosen.

The results from the present study were essentially descriptive in nature. Statistical analyses were performed using a Pearson correlation test, Fisher's exact test and Student's $t$-test.

\section{RESULTS}

The demographic data for the group of 160 patients with chronic migraine and 160 control subjects are presented in Table 1. The patients and controls were, on average, 51 years old, and females represented slightly more than half of each group. Caucasian ethnic ancestry was observed in $48 \%$ of the patients and $56 \%$ of controls.

Table 1. Demographic characteristics of patients with chronic migraine and controls.

\begin{tabular}{lcc}
\hline & Controls & Patients \\
\hline Males & $76(47.5 \%)$ & $71(44.4 \%)$ \\
Females & $84(52.5 \%)$ & $89(55.6 \%)$ \\
Average age (years) & $50.8 \pm 18.2$ & $50.7 \pm 16.7$ \\
Caucasian & $90(56.2 \%)$ & $77(48.1 \%)$ \\
Other ethnic background & $70(43.8 \%)$ & $83(51.9 \%)$ \\
\hline
\end{tabular}


The facial nerve studies showed no difference between patients and controls, and normal values were obtained for all individuals (Table 2). This result confirmed that no cases of lesions of the facial nerve had been included among the subjects of either group.

Table 3 shows the average results obtained for patients with chronic migraine and controls for the three waves of the blink reflex test. There were no significant differences in R1, $\mathrm{R} 2$, or R2c between the two groups and, in fact, the values were extremely similar; $p$ was close to 1.0 in all comparative calculations. When patients and controls were subdivided into groups according to gender and ethnicity (Table 4), the results remained unaltered, i.e. no differences were observed between patients and controls.

Table 2. Average results ( $\mathrm{mm}$ ) for registry of latency and amplitude responses of the facial nerve in controls and patients with chronic migraine. These results show that there were no lesions of the facial nerve that could influence the results from the blink reflex.

\begin{tabular}{lccccc} 
& \multicolumn{2}{c}{ Controls $(\mathrm{n}=160)$} & & \multicolumn{2}{c}{ Patients $(\mathrm{n}=160)$} \\
\cline { 2 - 3 } Column1 & $\begin{array}{c}\text { Right side } \\
\text { Controls }\end{array}$ & $\begin{array}{c}\text { Left side } \\
\text { Column2 }\end{array}$ & & $\begin{array}{c}\text { Right side } \\
\text { Patients }\end{array}$ & $\begin{array}{c}\text { Left side } \\
\text { Column3 }\end{array}$ \\
\hline $\begin{array}{l}\text { Average } \\
\text { latency }\end{array}$ & $2.19 \pm 0.82$ & $2.21 \pm 0.83$ & & $2.13 \pm 0.76$ & $2.20 \pm 0.74$ \\
$\begin{array}{l}\text { Average } \\
\text { amplitude }\end{array}$ & $3.27 \pm 1.43$ & $3.28 \pm 1.42$ & & $3.28 \pm 1.45$ & $3.30 \pm 1.43$ \\
\hline
\end{tabular}

\section{DISCUSSION}

The absence of biomarkers for a given disease is always frustrating. Several attempts have been, and continue to be, made to identify biomarkers that could confirm the diagnosis of a particular form of headache and also provide indirect information on therapeutic success or failure. It is possible that patients with episodic migraine may present alterations in the blink reflex, particularly regarding habituation to the stimulus ${ }^{3,4}$, but the literature diverges with regard to every other aspect of the role of the blink reflex for headaches. Episodic migraine with or without aura $^{4,6-12}$, tension-type headache $\mathrm{e}^{10,11,13}$, cluster headache ${ }^{5}$, cervicogenic headache ${ }^{11}$ and hypnic headache ${ }^{12}$ all presented negative or controversial information on the blink reflex responses. The present study adds to the previous reports of negative results when considering yet another headache type, i.e. chronic migraine ${ }^{16,17}$. For ethical reasons it was not possible to restrain patients from using pain medication, but severe neural dysfunction of the brainstem, if present, was not likely to have been affected by the analgesics and anti-inflammatory drugs.

In this large series of patients and controls there were no significant differences between the R1, R2, and R2c wave latencies. This suggests that the trigeminal nucleus in the pons may be fully functioning with regard to receiving, integrating and responding to the blink reflex in the vast majority

Table 3. Results from recordings (ms) of the blink reflex waves in controls and patients with chronic migraine. No significant differences were observed between the two sides of the same individual or between patients and controls ( $p$ values were all close to 1.0).

\begin{tabular}{lccccc} 
& \multicolumn{2}{c}{ Controls $(n=160)$} & & \multicolumn{2}{c}{ Patients $(n=160)$} \\
\cline { 2 - 3 } \cline { 5 - 6 } & Right side & Left side & & Right side & Left side \\
R1 & $10.245 \pm 0.908$ & $10.276 \pm 0.919$ & & $10.297 \pm 0.970$ & $10.290 \pm 0.934$ \\
R2 & $32.467 \pm 3.313$ & $32.473 \pm 3.300$ & & $32.440 \pm 3.271$ & $32.510 \pm 3.301$ \\
R2C & $34.501 \pm 3.320$ & $34.512 \pm 3.319$ & & $34.473 \pm 3.119$ & $34.345 \pm 3.123$ \\
\hline
\end{tabular}

Table 4. Results from controls and patients with headache, according to gender and ethnicity. No differences were observed in recordings of waves (ms) from the blink reflex.

\begin{tabular}{|c|c|c|c|c|c|c|}
\hline & \multicolumn{6}{|c|}{ Controls } \\
\hline & \multicolumn{2}{|c|}{$\mathrm{R} 1$} & \multicolumn{2}{|c|}{ R2 } & \multicolumn{2}{|c|}{ R2c } \\
\hline & Right side & Left side & Right side & Left side & Right side & Left side \\
\hline Males & $10.334 \pm 0.976$ & $10.345 \pm 0.960$ & $32.440 \pm 3.399$ & $32.448 \pm 3.421$ & $34.498 \pm 3.310$ & $34.510 \pm 3.330$ \\
\hline Females & $10.278 \pm 0.966$ & $10.304 \pm 0.962$ & $32.475 \pm 3.345$ & $32.480 \pm 3.350$ & $34.447 \pm 3.371$ & $34.467 \pm 3.380$ \\
\hline Caucasian & $10.342 \pm 0.915$ & $10.336 \pm 0.921$ & $32.470 \pm 3.276$ & $32.481 \pm 3.299$ & $34.492 \pm 3.303$ & $34.489 \pm 3.295$ \\
\hline \multirow[t]{4}{*}{ Other ethnic background } & $10.430 \pm 0.930$ & $10.350 \pm 0.929$ & $32.480 \pm 3.361$ & $32.473 \pm 3.360$ & $34.498 \pm 3.287$ & $34.530 \pm 3.331$ \\
\hline & \multicolumn{6}{|c|}{ Patients } \\
\hline & \multicolumn{2}{|c|}{ R1 } & \multicolumn{2}{|c|}{$\mathrm{R} 2$} & \multicolumn{2}{|c|}{$\mathrm{R} 2 \mathrm{c}$} \\
\hline & Right side & Left side & Right side & Left side & Right side & Left side \\
\hline Males & $10.369 \pm 0.981$ & $10.396 \pm 0.992$ & $32.340 \pm 3.393$ & $32.388 \pm 3.400$ & $34.401 \pm 3.216$ & $34.311 \pm 3.232$ \\
\hline Females & $10.301 \pm 0.986$ & $10.317 \pm 0.994$ & $32.487 \pm 3.335$ & $32.470 \pm 3.334$ & $34.498 \pm 3.278$ & $34.412 \pm 3.297$ \\
\hline Caucasian & $10.245 \pm 0.908$ & $10.276 \pm 0.919$ & $32.467 \pm 3.313$ & $32.473 \pm 3.330$ & $34.501 \pm 3.320$ & $34.512 \pm 3.319$ \\
\hline Other ethnic background & $10.298 \pm 0.990$ & $10.303 \pm 0.986$ & $32.498 \pm 3.299$ & $32.504 \pm 3.308$ & $34.497 \pm 3.230$ & $34.480 \pm 3.301$ \\
\hline
\end{tabular}


of patients. This is a very primitive and relatively simple reflex, and may remain unaltered even in patients who daily, or almost daily, suffer from headaches. It is possible that some patients indeed have alterations in their blink reflex wave patterns, but when a large cohort of subjects is studied, these few cases of alteration may be diluted in the pool of normal responses.

\section{References}

1. Tajti J, Szok D, Párdutz A, et al. Where does a migraine attack originate? In the brainstem. J Neural Transm 2012;119:557-568.

2. Overend W. Preliminary note on a new cranial reflex. Lancet 1986;1:619.

3. di Clementi L, Coppola G, Magis D, et al. Interictal habituation deficit of the nociceptive blink reflex: an endophenotypic marker for presymptomatic migraine? Brain 2007;130:765-770.

4. de Marinis M, Pujia A, Collaizo E, Accornero N. The blink reflex in chronic migraine. Clin Neurophysiol 2007;118:457-463.

5. Holle D, Zillessen S, Gaul C, et al. Habituation of the nociceptive blink reflex in episodic and chronic cluster headache. Cephalalgia 2012;32:998-1004.

6. Avramidis TG, Podikoglou DG, Anastasopoulos IE, Koutroumanidis MA, Papadimitriou AL. Blink reflex in migraine and tension-type headache. Headache 1998;38:691-696.

7. de Tommaso M, Guido M, Libro G, Sciruicchio V, Puca F. The three responses of the blink reflex in adult and juvenile migraine. Acta Neurol Belg 2000;100:96-102.

8. de Tommaso M, Murasecco D, Libro G, et al. Modulation of trigeminal reflex excitability in migraine: effects of attention and habituation on the blink reflex. Int J Psychophysiol 2002;44:239-249.

9. Yildirim G, Sayin R, Cogen EE, Odabas FO, Tombul T. Randomised, controlled blink reflex in patients with migraine and tension type headache. J Pak Med Assoc 2011;61:978-982.
10. Aktekin B, Yaltkaya K, Ozkaynak S, Oguz Y. Recovery cycle of the blink reflex and exteroceptive suppression of temporalis muscle activity in migraine and tension-type headache. Headache 2011;41:142-149

11. Sand T, Moll-Nielsen B, Zwart JA. Blink reflex R2 amplitudes in cervicogenic headache, chronic tension-type headache and migraine. Cephalalgia 2006;26:1186-1191.

12. Holle D, Gaul C, Krebs S, et al. Nociceptive blink reflex and painrelated evoked potentials in hypnic headache. Cephalalgia 2011;31:1181-1188.

13. Peddireddy A, Wang K, Svensson P, Arendt-Nielsen L. Blink reflexes in chronic tension-type headache patients and healthy controls. Clin Neurophysiol 2009;120:1711-1716.

14. Lipton RB. Chronic migraine, classification, differential diagnosis, and epidemiology. Headache 2011;51(Suppl 2):S77-S83.

15. Aurora SK, Kulthia A, Barrodale PM. Mechanism of chronic migraine. Curr Pain Headache Rep 2011;15:57-63.

16. Manack A, Turkel C, Silberstein S. The evolution of chronic migraine: classification and nomenclature. Headache 2009;49:1206-1213.

17. Negro A, Rocchietti-March M, Fiorillo M, Martelletti P. Chronic migraine: current concepts and ongoing treatments. Eur Rev Med Pharmacol Sci 2011;15:1401-1420. 